\title{
Peer-Led Culinary Skills Intervention for Adolescents: Pilot Study of the Impact on Knowledge, Attitude, and Self-efficacy
}

\author{
Amanda R. Oakley, MS, RD; Sarah A. Nelson, PhD; \\ Sharon M. Nickols-Richardson, PhD, RD
}

\begin{abstract}
Objective: To assess the impact and feasibility of a culinary skills intervention for adolescents led by peer educators compared with adult educators.

Methods: Adolescents (aged 11-14 years) were randomized to peer educator $(\mathrm{n}=22)$ or adult educator $(n=20)$ groups and attended 2 2.5-hour culinary skills lessons addressing knife skills, cooking methods, and recipes. Knowledge, attitude, and self-efficacy measurements were completed before and immediately after the intervention and at 3 and 6 months after the intervention. Fidelity checklists assessed the feasibility of program delivery. Differences within and between groups over time were assessed using ANOVA.

Results: Adolescents $(\mathrm{n}=42)$ increased knowledge $(3.7 \pm 2.6$ points $[$ mean $\pm \mathrm{SD}] ; P<.001)$, attitude $(0.8 \pm 4.5 ; P<.05)$, and self-efficacy of cooking $(2.6 \pm 5.3 ; P<.001)$ and cooking method $(1.7 \pm 4.6 ; P<.01)$ after intervention. Peer and adult educators were equally able to deliver the intervention.

Conclusions and Implications: Peers and adults can feasibly lead a culinary skills program for adolescents that increases knowledge. To affect attitude and self-efficacy, additional training of peer educators may be needed.

Key Words: adolescents, children, cooking, peer education, self-efficacy ( $J$ Nutr Educ Behav. 2017;49:852-857.)
\end{abstract}

Accepted July 11, 2017. Published online September 19, 2017.

\section{INTRODUCTION}

Culinary skills education within public schools has decreased in recent decades, leaving a noticeable gap in developing the life skill of cooking. ${ }^{1-3}$ To fill this deficit, food and nutrition experts have called for a resurgence in culinary skills nutrition education programs to improve basic knife skills, cooking methods, and use of common kitchen tools, utensils, and equipment, as well as recipe use, conversion, and kitchen math. These culinary skills may improve dietary quality and prevent early development of chronic diseases such as obesity in adolescence. $^{4-6}$ Numerous programs about culinary skills have been conducted, but few have reported outcomes after the intervention. ${ }^{7-25}$ Change in culinary skills knowledge is the most commonly reported measure from culinary-based education pro-

Department of Food Science and Human Nutrition, University of Illinois at UrbanaChampaign, Urbana, IL

Conflict of Interest Disclosure: The authors' conflict of interest disclosures can be found online with this article on www.jneb.org.

Address for correspondence: Sharon M. Nickols-Richardson, PhD, RD, Department of Food Science and Human Nutrition, University of Illinois at Urbana-Champaign, 905 S Goodwin Ave, 260 Bevier Hall, MC-182, Urbana, IL 61801; Phone: (217) 244-4498; Fax: (217) 265-0925; E-mail: nickrich@illinois.edu

(C)2017 The Authors. Published by Elsevier, Inc. on behalf of the Society for Nutrition Education and Behavior. This is an open access article under the CC BY-NC-ND license (http://creativecommons.org/licenses/by-nc-nd/4.0/).

grams. $^{7,10,11,13,16,24}$ Increases in knowledge and cooking skills selfefficacy, among other factors, have been connected to the foods that adolescents select. $^{26}$

Peer education has been suggested as a delivery mode for culinary skills education, because a variety of other programs have used peer education as a strategy to deliver community-based nutrition education. 3,27-29 However, the feasibility and acceptability of culinary skills nutrition education by means of peer leaders have not been formally evaluated in adolescent populations.

The purpose of this study was to test the impact and feasibility of 2 2.5-hour culinary skills lessons (ie, intervention) for adolescents on knowledge, attitude, and self-efficacy regarding culinary skills, a critical area within nutrition education. It was hypothesized that peer educators would lead lessons as well as adult educators, with similar results for participant outcome measures (knowledge, attitude, and self-efficacy) and for process observations. 


\section{METHODS}

\section{Intervention Pretesting and Modification}

This culinary skills intervention consisted of 2 sequential lessons that were developed using Social Cognitive Theory $^{30}$ and Experiential Learning Theory. ${ }^{31}$ These theories were selected based on the supposition that individuals learn by observing others (eg, peers, adults) via social and environmental contexts ${ }^{30}$ and by actively engaging in skill development ${ }^{31}$ to gain mastery and self-efficacy for the skill. ${ }^{30}$ Lessons were originally designed to teach the topics of knife skills, cooking methods, and following recipes related to fruits and vegetables. Each lesson included pretest measurements, instruction, hands-on practice, review, time for questions, and posttest measurements. The instructional portion of each lesson included activity-based discussions with educational handouts and leader demonstrations. Lesson 1 (Culinary Skills) focused on knife skills including safety, selection, and use, as well as cooking methods (tools, utensils, and equipment). Lesson 2 (Culinary Skills in Action) focused on hands-on knife skills, and following recipes and kitchen math skills, with review activities to reinforce concepts covered in both lessons. This intervention, including measurements, was evaluated for content validity by 8 experts and tested for fidelity with 7 girls led by 1 adult, with focus group followup for pretesting.

Lessons were minimally modified based on pretesting. ${ }^{32}$ Specific activities were streamlined to reduce preparation time and maximize experiential learning; other activities were modified to enhance participant safety and provide individualized feedback. Intervention objectives were retained and included applying appropriate cutting and cooking methods for fruits and vegetables, demonstrating safety in the kitchen, and preparing recipes with fruits and vegetables.

Self-efficacy was the primary construct of Social Cognitive Theory reinforced by lesson content and activities. $^{30}$ All aspects of Experiential Learning Theory were touched upon, primarily concrete experience and active experimentation, as small group recipe preparation reinforced active experimentation, whereas group review, discussions, and games applied abstract conceptualization. ${ }^{31}$

\section{Setting}

The current intervention took place in a university instructional foods laboratory classroom with tables for lecture and demonstrations as well as several small kitchen units, each of which included an oven with a range, sink, measuring cups, mixing bowls, skillets, and other kitchen utensils. The classroom setting allowed participants to work in small groups in the kitchen units with space to view demonstrations and participate in discussions and reviews.

\section{Educators}

Peer educators and adult educators were recruited through electronic mailings describing an opportunity to lead culinary skills lessons for 11- to 14year-olds, covering the topics of basic knife skills, cooking methods, and following recipes. Eligible peer educators aged 14-15 years and adult educators aged $>25$ years expressed interest and were screened for availability. Prospective educators were excluded if they had received professional culinary training, because the intervention was designed for a lay community leader. Prospective educators were interviewed and selected based on strong interpersonal, communication, and leadership skills as well as composure, as desirable personal attributes of role models to be emulated by adolescents. Educators successfully completed a background check and attended a 3-hour training before leading the intervention. One researcher trained all educators. Training addressed all technical components of each lesson by following the detailed lessons stepby-step and by addressing questions, kitchen familiarization, and group discussion of presentation methods including interactive demonstrations, pausing to ask for questions and addressing participant safety. Emphasis was placed on technical components and on review of the lesson activities to reinforce intervention objectives with the educators. Understanding and proficiency were demonstrated by educators by answering questions accurately and using proper techniques during the training, as evaluated by the trainer. Educators were compensated with a gift certificate of $\$ 50$ for completing training and $\$ 45$ per lesson led (for a total of \$140).

\section{Participants and Recruitment}

From April to July, 2015, a convenience sample of adolescents entering the sixth and seventh grades (or aged 11-14 years) who were interested in learning about culinary skills were recruited from the Urbana-Champaign, IL area. Each interested adolescent and his or her parent or guardian attended an informational meeting to learn about the intervention and completed informed written consent and assent forms, respectively. Exclusion criteria included adolescents aged $<11$ or $>14$ years and parent's or guardian's inability to transport his or her child to the intervention site. Participants were assigned to the peer educator group (PEG) or adult educator group (AEG), based on their schedule preferences and availability; times were randomized to include morning, afternoon, and evening session options. Participants received a $\$ 5$ gift certificate for each lesson that was completed ( $\$ 10$ for the intervention). Three- and 6-month postintervention data were collected by mail or in person at the parent's or guardian's preference. No additional compensation was provided for these measures. The study protocol (No. 15443) was approved by the Institutional Review Board for the Protection of Human Subjects of the University of Illinois at Urbana-Champaign.

\section{Measurements}

Adolescents completed measurements at 4 time points: before and immediately after the intervention and 3 and 6 months after the intervention. Measurements included questions pertaining to culinary skills knowledge, attitude toward cooking, cooking selfefficacy, and cooking methods selfefficacy. Instruments were internally reliable (Cronbach $\alpha=.72$ for knowledge, attitude $=.71$, cooking selfefficacy $=.84$, and cooking methods self-efficacy $=.81$ ). The researchers 
collected demographic data after collecting parent/guardian consent and youth assent forms at the informational meeting.

Knowledge was measured using the sum of correct responses to 19 multiple choice questions (range, 019 points). Questions focused on concepts covered within lessons, including knife selection, knife safety, cooking methods, and following recipes (eg, You would use the cooking instrument in the following picture [saucepan] for all cooking methods except . [correct choice, boiling]). Attitude toward cooking was measured using responses from 11 statements on a 5-point Likert scale (strongly disagree to strongly agree); higher scores (range, 11-55 points) indicated a more positive attitude toward cooking (eg, It is important that I know how to prepare food.). Cooking self-efficacy was measured using responses from 10 statements on a 5-point Likert scale (range, 10-50 points), with higher scores indicating higher self-efficacy toward cooking (eg, use basic cooking techniques). Cooking method selfefficacy was measured from responses to 7 cooking methods (eg, boiling) on a 5-point Likert scale (range, 7-35 points), with higher scores indicating higher self-efficacy of the cooking methods discussed. Self-efficacy scales ranged from not at all confident to extremely confident. Cooking methods included in measurements corresponded to those covered in the intervention.

Fidelity checklists were completed for each lesson. ${ }^{33}$ Checklist items included lesson length, completion of each activity, and overall lesson comments. Additional checklist questions included Leaders asked if participants had any questions, Leader was familiar with lesson, and Leader was able to keep participants on topic/task. All checklist items were selected to understand lesson flow and contained yes or no responses with a column for comments to eliminate observer subjectivity.

\section{Data Analyses}

The researchers performed descriptive statistics on demographic data (preintervention) and collected measurements at each of the 4 intervention intervals. Demographic data and preintervention measurements were compared using independent $t$ tests and Pearson chi-square test for independence to determine group variance and differences between sessions of the same intervention group. Differences within and between groups over time were assessed using a $2 \times 4$ ( 2 intervention groups $\times 4$ intervals) (ANOVA) with repeated measures on the time factor. In the case that sphericity was violated, the GreenhouseGeisser correction was used. Data from missing time points were filled using the last observation carried forward method. ${ }^{34}$ Significance was set at $P<.05$. All data analyses were conducted using the Statistical Package for the Social Sciences (version 22.0, SPSS, IBM Corp, Armonk, NY, 2013).

\section{RESULTS}

Contact was made by 116 parents and guardians of adolescents, with 50 youth-parent pairs attending informational meetings. After 49 completed informed consent and assent, 46 adolescents attended the first lesson; 42 adolescents completed the full intervention (included in data analyses). The Figure depicts participant recruitment and retention from initial contact through 6 months postintervention.

A total of 22 and 20 participants were in the PEG and AEG, respectively. Of the 42 participants who completed the intervention, race/ethnicity was reported as non-Hispanic white $(\mathrm{n}=24)$, Asian $(\mathrm{n}=2)$, non-Hispanic black $(\mathrm{n}=6)$, and other including multiracial $(\mathrm{n}=10)$ (nonsignificant for PEG vs AEG; $P=.72$ ). There were equal numbers of male $(\mathrm{n}=21)$ and female ( $\mathrm{n}=21$ ) participants (nonsignificant for PEG vs AEG; $P=.54$ ). There was no significant difference in the age of adolescents in the PEG $(n=22$ $[$ mean $\pm \mathrm{SD}$ ] $12.4 \pm 1.1$ years $)$ compared with AEG ( $\mathrm{n}=20$; $11.9 \pm 1.0$ years $)(P=.10)$.

The intervention was conducted for 2 PEGs and 2 AEGs to accommodate all participants while keeping the attendance appropriate for adolescents to observe actively and participate in the intervention. Attendance ranged from 9 to 13 participants/ lesson.

\section{Measurements}

There were no significant differences between groups for knowledge $(P=.84)$, attitude $(P=.76)$, cooking self-efficacy $(P=.33)$, or cooking methods self-efficacy $(P=.28)$ at preintervention (Table 1). There was a significant difference in preintervention or baseline knowledge score only for the PEG between the 2 intervention offerings of PEG $(P=.04)$; however, there were no significant differences observed at postintervention or 3 or 6 months postintervention with any other measurements or group offerings at any interval.

There was a significant effect of time on knowledge $(P<.001)$, culinary skills self-efficacy $(P=.001)$, and cooking methods self-efficacy $(P=.005)$ but not on attitude $(P=.06)$ after the intervention (Table 1). Within the PEG, knowledge was the only variable that significantly increased from before to after the intervention; this increase was maintained at 3 and 6 months postintervention. The AEG was similar to the PEG for knowledge, but attitude and both self-efficacy measurements also had significant increases from before to after the intervention, although these increases were not sustained at 3 or 6 months postintervention. Self-efficacy measurements for all participants significantly decreased from post to 3 months postintervention for cooking self-efficacy and from post to 6 months postintervention for cooking methods self-efficacy. There were no significant group $\times$ time interactions for any measurements.

\section{Process Observation}

Fidelity checklists completed during each lesson indicated an average lesson length of $154 \pm 11.9$ minutes for the PEG and $155 \pm 15.8$ minutes for the AEG $(P>.05)$. Both peer and adult educators kept participants on task and completed all planned activities during each lesson. Table 2 summarizes items of concern from the fidelity checklist. Process observation checklist comments indicated that peer educators were occasionally fast paced when completing worksheets and their demonstrations were not always easy for all participants to see. 


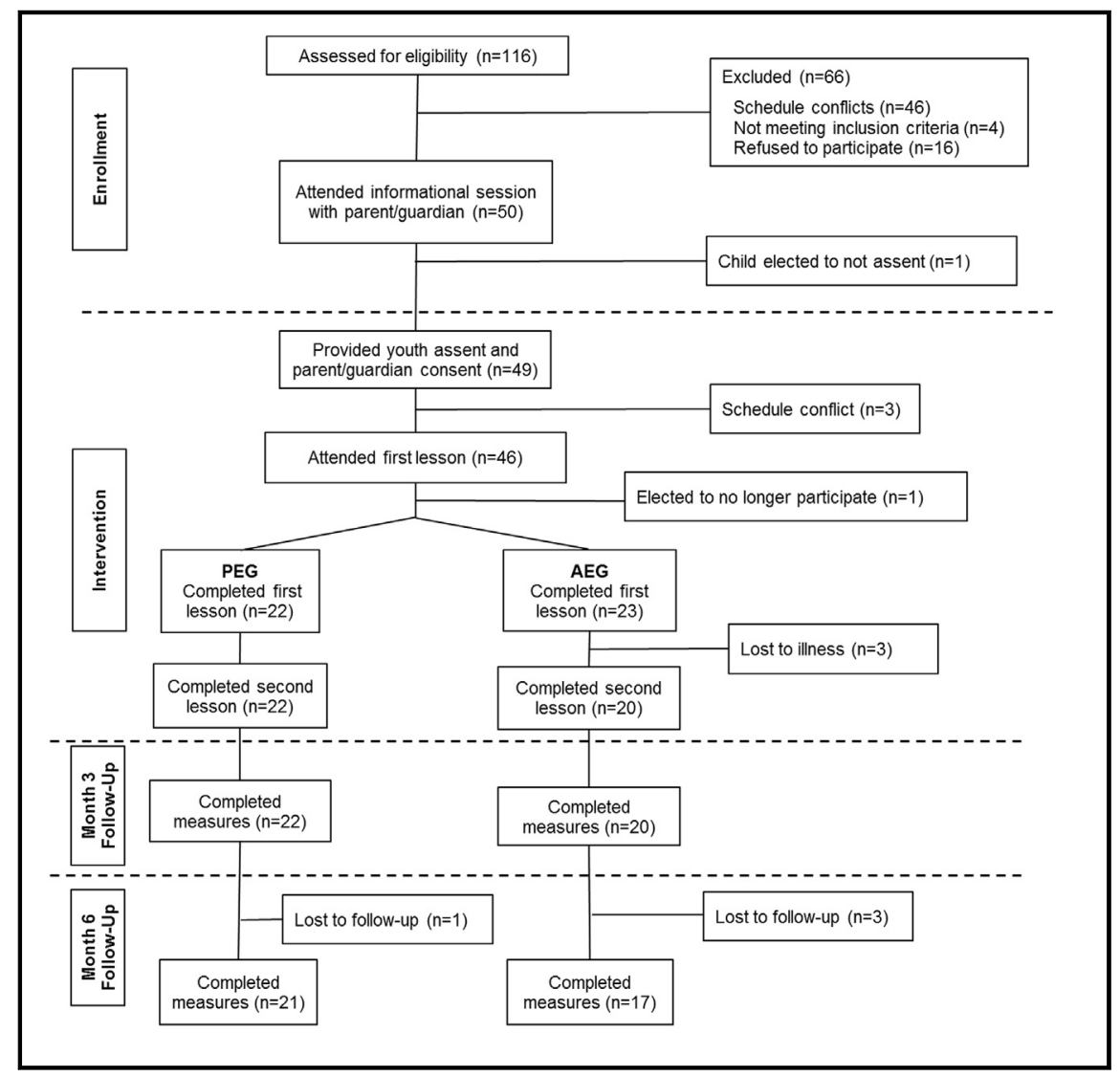

Figure. Participant recruitment and retention in a pilot study of a culinary skills intervention delivered by peer educators, compared with adult educators, to 11- to 14-year-old adolescents $(n=42)$. AEG indicates adult educator group; PEG, peer educator group.

In addition, peer educators were noted to be more informal when leading the lessons, compared with adult educators. Both peer and adult educators incorporated methods of review to reinforce lesson content. All activities were completed but peereducators did not always discuss the concept of why there were certain correct answers in activities, whereas the adult educators explained correct answers to participants. Peer educators were occasionally noted to have briefly used incorrect cutting form while leading some lesson activities.

\section{DISCUSSION}

In support of the hypothesis, peer education proved to be feasible and comparable to that of adult education, which supports that adolescent peer culinary skills education can serve as a novel education technique. ${ }^{29}$ Importantly, peer educators require additional training, beyond 3 hours, to develop further presentation and technical skills required. Presentation skills of peer educators can be enhanced with proper pacing of lessons, an explanation of correct answers during review of information, and demonstration of techniques for all to observe optimally. Regarding technical skills, peer educators require additional training primarily centered on knife handling and safety. Additional training will further develop the confidence of peers to lead the lessons for their counterparts.

Culinary skills programs that included evaluations assessed various outcomes including dietary intake behaviors in addition to those included in the current intervention. Five interventions found increases in knowledge and included significant, ${ }^{7,16}$ unspecified, $^{11,13}$ and nonsignificant ${ }^{10}$ changes compared with baseline. The current intervention of approximately 5 hours was sufficient for significant and sustained increases in knowledge from baseline through 6 months after the intervention when delivered by a peer or an adult. Participant attitude toward cooking was assessed by 3 programs, ${ }^{7,20,24}$ with no significance noted. Increases in self-efficacy from before the intervention to after it were observed in 4 studies; 2 reported significant increases, ${ }^{9,10} 1$ an unspecified increase, $^{24}$ and 1 a nonsignificant increase. ${ }^{7}$ The current intervention showed similar mixed results, with overall significant increases in selfefficacy from before to after the intervention but no longer-term retention. Learning through observation also was linked to increased self-efficacy when an adult demonstrated a given task. ${ }^{35}$ Little evidence exists regarding the link between observational learning and changes in self-efficacy when peer educators demonstrate comparable skills. Of previous program interventions, $^{7-13,15-25,36,37}$ only 1 program $^{25}$ included longer-term followup testing.

Participation was limited to youth with access to the intervention site via a parent or guardian, which could have limited adolescents who did not have available transportation. There was no control group within this intervention, because a key unit of comparison was the mode of education delivery. Lessons held in a university classroom and in late summer could have facilitated or hindered attentiveness compared with a community site or after a full day of formal school instruction. It is unclear whether the dose of culinary skills education (ie, 5 hours), the lack of reinforcement, or a combination of these 2 factors was the reason for attitude and selfefficacy measurements not being sustained over time. One limitation of psychometric data collection included that of social desirability, particularly in an early adolescent population. In addition, the researchers were not able to conduct a power analysis to determine the target sample size for this pilot study; thus, further studies are needed.

\section{IMPLICATIONS FOR RESEARCH AND PRACTICE}

The lack of sustained attitude and selfefficacy scores over time may reflect 
Table 1. Measurements of Knowledge, Attitude, Cooking Self-efficacy, and Cooking Methods Self-efficacy in 11- to 14-Year-Old Adolescents $(n=42)$ Before and After a Culinary Skills Intervention Delivered by Peer Educators, Compared With Adult Educators

\begin{tabular}{|c|c|c|c|c|c|}
\hline Variable $^{a}$ & $\begin{array}{l}\text { Preintervention } \\
\text { (mean } \pm \text { SD) }\end{array}$ & $\begin{array}{l}\text { Postintervention } \\
\quad(\text { mean } \pm \text { SD) }\end{array}$ & $\begin{array}{c}3 \text { Mo } \\
\text { Postintervention } \\
\text { (mean } \pm \text { SD) }\end{array}$ & $\begin{array}{c}6 \text { Mo } \\
\text { Postintervention } \\
\text { (mean } \pm \text { SD) }\end{array}$ & $\boldsymbol{P}$ \\
\hline \multicolumn{6}{|c|}{ Knowledge score (range, 0-19) } \\
\hline All & $12.0 \pm 2.3$ & $15.7 \pm 2.0^{* *}$ & $16.3 \pm 1.6^{* *}$ & $16.5 \pm 1.6^{* *}$ & Group $=$ NS \\
\hline PEG & $12.1 \pm 2.3^{*}$ & $15.2 \pm 1.9^{* *}$ & $15.7 \pm 2.1^{\star *}$ & $16.3 \pm 1.8^{* *}$ & Time $<.001$ \\
\hline AEG & $11.9 \pm 2.6$ & $16.2 \pm 2.0^{* *}$ & $16.7 \pm 1.5^{\star \star}$ & $16.7 \pm 1.5^{\star \star}$ & $\mathrm{G} \times \mathrm{T}=\mathrm{NS}$ \\
\hline \multicolumn{6}{|c|}{ Attitude score (range, 11-55) } \\
\hline All & $44.2 \pm 4.2$ & $45.4 \pm 4.7^{* *}$ & $44.5 \pm 5.6$ & $43.7 \pm 5.3$ & Group $=$ NS \\
\hline PEG & $43.4 \pm 4.4$ & $43.8 \pm 4.1$ & $44.5 \pm 5.3$ & $43.3 \pm 4.7$ & Time $=\mathrm{NS}$ \\
\hline$A E G$ & $45.2 \pm 4.0$ & $47.1 \pm 4.7^{* \star}$ & $44.7 \pm 5.9$ & $44.5 \pm 5.8$ & $\mathrm{G} \times \mathrm{T}=\mathrm{NS}$ \\
\hline \multicolumn{6}{|c|}{ Cooking self-efficacy score (range, 10-50) } \\
\hline All & $41.8 \pm 5.6$ & $44.4 \pm 5.1^{\star *}$ & $42.1 \pm 5.3^{\star \star \star}$ & $43.3 \pm 5.3$ & Group $=$ NS \\
\hline PEG & $41.4 \pm 5.0$ & $43.4 \pm 5.1$ & $41.9 \pm 5.0$ & $43.0 \pm 5.9$ & Time $=.001$ \\
\hline AEG & $42.2 \pm 6.3$ & $45.5 \pm 5.0^{\star \star}$ & $42.2 \pm 5.6$ & $43.7 \pm 4.9$ & $\mathrm{G} \times \mathrm{T}=\mathrm{NS}$ \\
\hline \multicolumn{6}{|c|}{ Cooking methods self-efficacy score (range, 7-35) } \\
\hline All & $28.0 \pm 4.7$ & $29.7 \pm 4.5^{\star *}$ & $28.4 \pm 4.3$ & $27.9 \pm 4.7^{\star * \star *}$ & Group $=$ NS \\
\hline PEG & $27.8 \pm 5.6$ & $29.1 \pm 3.3$ & $28.6 \pm 4.3$ & $27.2 \pm 5.2$ & Time $=.005$ \\
\hline$A E G$ & $28.2 \pm 4.9$ & $30.5 \pm 4.4^{\star *}$ & $28.7 \pm 4.5$ & $28.2 \pm 4.2$ & $\mathrm{G} \times \mathrm{T}=\mathrm{NS}$ \\
\hline
\end{tabular}

AEG indicates adult education group; $\mathrm{G} \times \mathrm{T}$, group $\times$ time interaction; NS, not significant; PEG, peer education group.

${ }^{\mathrm{a}}$ For scores, all $\mathrm{n}=42$; PEG $\mathrm{n}=22$; and $\mathrm{AEG} n=20$; ${ }^{\star} P<.05$ between session of the same group at preintervention; ${ }^{* *} P<.05$ increase from preintervention; ${ }^{* \star \star} P<.05$ decrease from postintervention to 3 mo postintervention; ${ }^{\star \star \star \star} P<.01$ decrease from postintervention to 6 mo postintervention.

the length of the intervention or the lack of reinforcement, which were not measured. Reinforcement could have occurred at home via parents, but parental encouragement or engagement was not included in the current intervention. Further studies with control groups are needed to determine whether a sustained increase in attitude and self-efficacy is fostered by parental reinforcement of skills taught during an intervention. Moreover, reinforcement may occur through training of peers in the PEG. Although it was not tested in this study, other investigators have shown that peer educators have significant changes in pre- to post-intention, self-efficacy, and attitude. ${ }^{28}$ In addition, it is possible that peer educators may have received additional personal or professional development benefits from leading the intervention, but these data were not collected. Future studies should examine the benefits or perceived benefits of leading culinary skills interventions by peer educators.

Peers and adults are both capable of leading a culinary skills intervention for 11- to 14-year-olds that results in increased knowledge in the short term and long term (6 months). To increase attitude and self-efficacy of culinary skills in adolescents immediately after the intervention, compared with adult educators, peer educators may require additional training for specific aspects such as knife safety and presentation skills.

\section{ACKNOWLEDGMENTS}

Segments of these findings were presented in poster format at the Society for Nutrition Education and Behavior Annual Conference 2016 and Experimental Biology 2016. This material was based on work supported by the National Institute of Food and

Table 2. Fidelity Checklist Items for a Culinary Skills Intervention Delivered by Peer Educators and Adult Educators to 11- to 14Year-Old Adolescents ( $n=42)$

Indicators (for Educators)

Emphasized fruit and vegetable consumption

Completed all planned lesson activities

Maintained appropriate pace through most of lesson

Kept participants on task

Asked participants to verbalize questions

Total
Peer Educator Group, n (\%)

$2(50)$
$4(100)$
$4(100)$
$4(100)$
$3(75)$
$17(85)$

Adult Educator Group, n (\%)

$$
\begin{gathered}
3(75) \\
4(100) \\
4(100) \\
4(100) \\
3(75) \\
18(90)
\end{gathered}
$$

Note: Feasibility was determined using a threshold of $>80 \%$ as rated by the process observer. 
Agriculture, US Department of Agriculture (USDA), under Award No. 2012-68001-22032. Any opinions, findings, conclusion, or recommendations expressed in this publication are those of the authors and do not necessarily reflect the view of the USDA.

\section{REFERENCES}

1. Lavelle F, Spence M, Hollywood L, et al. Learning cooking skills at different ages: a cross-sectional study. Int J Behav Nutr Phys Act. 2016;13:119.

2. Lichtenstein AH, Ludwig DS. Bring back home economics education. J Am Med Assoc. 2010;303:1857-1858.

3. Nelson SA, Corbin MA, NickolsRichardson SM. A call for culinary skills education in childhood obesityprevention interventions: current status and peer influences. J Acad Nutr Diet. 2013;113:1031-1036.

4. Condrasky MD, Hegler M. How culinary nutrition can save the health of a nation. J Ext. 2010;42:2COM1.

5. US Department of Health and Human Services and US Department of Agriculture. Dietary Guidelines for Americans 2015-2020. https://health.gov/ dietaryguidelines/2015/resources/20152020_Dietary_Guidelines.pdf. Accessed November 21, 2016.

6. USDA and US Department of Health and Human Services. Dietary Guidelines for Americans, 2010. 7th ed. Washington, DC: US Government Printing Office; 2010.

7. Beets MW, Swanger K, Wilcox DR, Cardinal BJ. Using hands-on demonstrations to promote cooking behaviors with young adolescents: the Culinary Camp summer cooking program. J Nutr Educ Behav. 2006;39:288-289.

8. Brown BJ, Hermann JR. Cooking classes increase fruit and vegetable intake and food safety behaviors in youth and adults. J Nutr Educ Behav. 2005;37: 104-105.

9. Caraher M, Seeley A, Wu M, Lloyd S. When chefs adopt a school? An evaluation of a cooking intervention in English primary schools. Appetite. 2013; 62:50-59.

10. Chessen J, Nicholson LM, Sklar J, McDermott AY. The development and pilot of a culinary intervention designed using the social cognitive theory to teach nutrition to adolescent girls. J Nutr Educ Behav. 2009; 41:S16.
11. Clark L, Foote RA. Building basic living skills in youth-Kid's Chef School. J Ext. 2004;42:3IA W5.

12. Concannon M, Rafferty E, SwansonFarmarco C. Snacks in the Stacks: teaching youth nutrition in a public library. J Ext. 2011;49:5IA W1.

13. Condrasky M, Wall-Bassett E, Frost S. "What's Cooking?" Culinary nutrition education at the supermarket. J Nutr Educ Behav. 2008;40:S73-S74.

14. Corr AQ, Condrasky M. Culinary nutrition in action is a SNAP! J Nutr Educ Behav. 2010;42:S100.

15. Condrasky M, Quinn A, Cason K. Cooking Camp provides hands-on nutrition education opportunity. J Culin Sci Technol. 2007;5:37-52.

16. Dixon JE, Condrasky MD, Sharp LJ, et al. Cooking confidence and healthy eating choices of preadolescent participants at a cooking camp. Top Clin Nutr. 2013;28:21-33.

17. Dougherty K, Silver C. Chef-nutritionist teams spark enjoyment and learning in cooking education series for 8- to 12-year-olds. J Nutr Educ Behav. 2007;39:237-238.

18. Heim S, Stang J, Ireland M. A garden pilot project enhances fruit and vegetable consumption among children. J Am Diet Assoc. 2009;109:1220-1226.

19. Hyland R, Stacy R, Adamson A, Moynihan P. Nutrition-related health promotion through an after-school project: the responses of children and their families. Soc Sci Med. 2006;62:758-768.

20. Liquori T, Koch PD, Contento IR, Castle J. The Cookshop Program: outcome evaluation of a nutrition education program linking lunchroom food experiences with classroom cooking experiences. J Nutr Educ. 1998;30:302-313.

21. Robson SM, Stough CO, Stark LJ. The impact of a pilot cooking intervention for parent-child dyads on the consumption of foods prepared away from home. Appetite. 2016;99:177-184.

22. Thomas HM, Irwin JD. Cook It Up! A community-based cooking program for at-risk youth: overview of a food literacy intervention. BMC Res Notes. 2011;4:495.

23. Thonney PF, Bisogni CA. Cooking Up Fun! A youth development strategy that promotes independent food skills. J Nutr Educ Behav. 2006;38:321-323.

24. Timmins C, Lambden E. Evaluation of Get Cooking! enhanced pilot (April 2004) research report. Cardiff, Wales: Beaufort Research; 2004.

25. Fulkerson JA, Neumark-Sztainer D, Story M, et al. The Healthy Home
Offerings via the Mealtime Environment (HOME) Plus study: design and methods. Contemp Clin Trials. 2014; 38:59-68.

26. Holsten JE, Deatrick JA, Kumanyika S, Pinto-Martin J, Compher CW. Children's food choice process in the home environment: a qualitative descriptive study. Appetite. 2012;58:64-73.

27. Layzer C, Rosapep L, Barr S. A peer education program: delivering highly reliable sexual health promotion messages in schools. J Adolesc Health. 2014; 54(3 suppl):S70-S77.

28. Stock S, Miranda C, Evans S, et al. Healthy Buddies: a novel, peer-led health promotion program for the prevention of obesity and eating disorders in children in elementary school. Pediatrics. 2007;120:e1059-e1068.

29. Nelson SA, Nickols-Richardson SM. A systematic review of peer nutrition education in childhood and adolescence. Health Behav Policy Rev. 2014;1:247-264.

30. Bandura A. Social Foundations of Thought and Action: A Social Cognitive Theory. Englewood Cliffs, NJ: Prentice Hall; 1986.

31. Kolb AY, Kolb DA. Experiential Learning Theory. In: Seel NM, ed. Encyclopedia of the Sciences of Learning. Boston, MA: Springer; 2012:1215-1219.

32. Nelson SA. Development and Evaluation of Lessons and Psychometric Tools for Peer-led Nutrition Education Interventions in Childhood and Adolescence (Dissertation). http://etda.libraries.psu.edu/ catalog/18214. Accessed July 1, 2015.

33. Story M, Lytle LA, Birnbaum AS, Perry CL. Peer-led, school-based nutrition education for young adolescents: feasibility and process evaluation of the TEENS study. J Sch Health. 2002; 72:121-127.

34. Saha C, Jones MP. Bias in the last observation carried forward method under informative dropout. J Stat Plan Inference. 2009;139:246-255.

35. Schunk DH, Hanson AR. Peer models: influence on children's self-efficacy and achievement. J Educ Psychol. 1985;77: 313-322.

36. Domel SB, Baranowski T, Davis $\mathrm{H}$, Leonard SB, Riley P, Baranowski J. Measuring fruit and vegetable preferences among 4th- and 5th-grade students. Prev Med. 1993;22:866-879.

37. Kohlstadt IC, Steeves ETA, Rice K, Gittelsohn J, Summerfield LM, Gadhoke P. Youth peers put the "invent" into NutriBee's online intervention. Nutr J. 2015;14:60-68. 
857.e1 Oakley et al

\section{CONFLICT OF INTEREST}

The senior author (S.M.N.-R.) has received research funding from the

Journal of Nutrition Education and Behavior • Volume 49, Number 10, 2017

USDA, National Institute of Food and Agriculture; the Bell Institute of Nutrition and Health, General Mills, Inc.; Dairy Management Institute; and McCormick Science Institute within the past 3 years. The first 2 authors do not have any conflicts of interest related to this study. 